\title{
Role of the COP9 Signalosome in Gastrointestinal Cancers
}

Sandra Jumpertz ${ }^{1}$, Jürgen Bernhagen ${ }^{1^{*}}$ and Anke K. Schütz ${ }^{1^{*}}$

${ }^{1}$ Institute of Biochemistry and Molecular Cell Biology, RWTH Aachen University, Pauwelsstraße 30, 52074 Aachen, Germany

*Corresponding author: Anke K. Schütz, Institute of Biochemistry and Molecular Cell Biology, Pauwelsstraße 30, 52074 Aachen, Germany; Tel: +49 241 80-85096; Fax: +49 241 80-82427; E-mail: anschuetz@ukaachen.de

Jürgen Bernhagen, Institute of Biochemistry and Molecular Cell Biology, Pauwelsstraße 30, 52074 Aachen, Germany; Tel: +49 $24180-88831$; Fax: +49 241 80-82427; E-mail: jbernhagen@ukaachen.de

Received date: Sep 11, 2014, Accepted date: Dec 27, 2014, Published date: Dec 30, 2014

Copyright: ( 2014 Jumpertz S, et al. This is an open-access article distributed under the terms of the Creative Commons Attribution License, which permits unrestricted use, distribution, and reproduction in any medium, provided the original author and source are credited.

\begin{abstract}
The COP9 signalosome (CSN) is an evolutionarily conserved multi-protein complex found in plants and animals. In mammals, the CSN consists of eight subunits (CSN1-CSN8). It has been suggested to play a key role in tumorigenesis, because its subunits are frequently overexpressed in human cancers and because the CSN is involved in the regulation of a number of processes that are relevant to carcinogenesis and cancer progression, e.g. cell cycle control, signal transduction, and apoptosis. The best-studied biochemical function of the CSN is the control of cellular protein stability via the ubiquitin-proteasome system through regulation of cullin-RING E3 ligase (CRL) activity by deNEDDylation of cullins or by the deubiquitination function of the CSN. Through these activities, the CSN regulates the degradation of several tumor suppressors and oncogenes that are degraded by the $26 \mathrm{~S}$ proteasome. This review summarizes recent findings that support CSN's role as a potential key player in tumorigenesis in general, but particularly focuses on evidence on the role of the CSN in gastrointestinal cancers. We cover links to tumorigenesis in the liver, stomach, pancreas, and colon, gathering and discussing findings about CSN's expression and its functional impact on cancer development and progression.
\end{abstract}

Keywords: COP9 signalosome; CSN; Gastrointestinal cancer; Hepatocellular carcinoma; Gastric cancer; Pancreatic cancer; Colorectal cancer; JAB1; Deneddylation

\section{The COP9 Signalosome (CSN)}

The constitutive photomorphogenesis 9 (COP9) signalosome (CSN) is an evolutionarily conserved multi-subunit protein complex that regulates pivotal cellular processes such as the cell cycle and apoptosis, as well as a number of oncogenic signal transduction pathways. In 1996, Chamovitz et al. first purified the COP9 complex from plants and characterized it as a repressor of dark-grown growth patterns, thus the name "constitutive photomorphogenesis" [1]. An orthologous $450-\mathrm{kDa}$ complex consisting of eight proteins was isolated from human erythrocytes and pig spleen two years later and found to contain the protein c-Jun-activation-domain-binding protein-1 (JAB1) [2,3]. JAB1 had been identified independently of the CSN complex and found to facilitate the binding of c-Jun or JunD to AP-1 sites, thereby acting as a co-activator of AP-1-regulated gene transcription [4]. To date, the CSN has been identified in various eukaryotes, including different fungus species [5-8], Caenorhabditis elegans [9], and Drosophila melanogaster [10]. The name "COP9 signalosome" and the nomenclature of its subunits was unified for the different species by Deng and colleagues in 2000, designating the subunits CSN1 to CSN8 according to their molecular weight [11]. While monomeric CSN5/JAB1 can exist independently of the complex, the other CSN subunits are exclusively found in the whole complex or as part of smaller sub-complexes [12-14]. CSN subunits 1, 2, 3, 4, 7 and 8 harbor a so-called PCI (proteasome, COP9 signalosome, translation initiation factor) domain whereas CSN5 and CSN6 contain an MPN (Mprlp-Pad1-N-terminal) domain instead $[15,16]$. Sharon et al. developed a model of the CSN complex based on a mass spectrometry approach suggesting that the CSN could be organized in two clusters with $\mathrm{CSN} 1 / 2 / 3 / 8$ on one side and with CSN4/5/6/7 forming the other cluster. In this model, the two clusters are connected by a single link constituted by a CSN1-CSN6 axis [13]. During the preparation of this article, the crystal structure of the human CSN was resolved at a resolution of $3.8 \AA$. The structure gives spectacular insight into the architecture of this protein complex and shows that the PCI proteins form an 18-stranded composite $\beta$-sheet at the centre of the complex which has a horseshoe-shaped appearance. Located across the PCI ring is a helical bundle of the CSN subunits with the MPN-containing subunits CSN5 and CSN6 at its core, the latter forming an intimate dimer [17]. Notably, only CSN5 contains a JAMM (Jab1/CSN5 MPN metalloenzyme) motif that is placed within its MPN domain, and which is critical for the $\mathrm{Zn}^{2+}$-dependent metalloproteinase activity of CSN5 [18]. Through this enzymatic activity, the CSN can cleave NEDD8 (neural precursor cell expressed developmentally down-regulated 8)-conjugates from cullin-RING ligases (CRLs), a process named "deNEDDylation" [19, 20]. CRLs are a large family of multi-subunit E3 ubiquitin ligases assembled on a cullin scaffold. By exchange of various substrate-specific, associated Fbox proteins, CRLs have a wide variety of substrates which they ubiquitinate for subsequent proteasomal degradation by the $26 \mathrm{~S}$ proteasome [21]. By the CSN-dependent removal of NEDD8 from cullins, CRLs are inactivated in short term, as evidenced by biochemical in vitro experiments [22,23], whereas in vivo experiments in the context of living cells showed that NEDDylation/ deNEDDylation cycles are essential for CRL stability and activity [19]. Together, this indicates that the CSN is an important regulator of protein turnover. Moreover, the CSN regulates other E3 ubiquitin ligases such as MDM2 (mouse double minute 2 homolog) and COP1 (constitutively photomorphogenic 1 ) that target p53, 14-3-3 $\sigma$, or c-Jun [24-26]. Additionally, the CSN has been shown to associate with 
USP15, a deubiquitinase (DUB) involved in NF- $\kappa B$ signaling [27]. Furthermore, by its association with different kinases, the CSN is involved in the phosphorylation of targets such as c-Jun and NF- $\mathrm{KB}$ [2]. Recently, the CSN has been linked to diverse disease conditions, e.g. atherosclerosis [28,29], HIV infection [30], cardiomyopathies [31], and microbial sepsis [32].

\section{The CSN and its Potential Role in Cancer}

Cancer diseases still belong to the most challenging human diseases that are associated with high mortality rates and that are difficult to cure with still only limited knowledge about the mechanisms of their development.

The CSN is a potential key player in tumorigenesis and its subunits are often overexpressed in tumors. For example, CSN5/JAB1 is overexpressed in different tumor entities, e.g. neuroblastoma [33], ovarian tumors [34,35], mamma carcinoma [36,37], hepatocellular carcinoma [38,39], pancreatic cancer [40], lung adenocarcinoma [41], or malignant thyroid lymphoma [42]. The CSN5 gene is rarely mutated, but its amplification was identified in hepatocellular carcinoma and breast tumors $[39,43]$. Protein and mRNA analysis in tumor lysates showed that CSN4 is overexpressed in prostate tumors [44]. An amplification of the CSN6 gene was identified in human breast cancer samples and in 17 breast cancer cell lines, and CSN6 protein levels were higher in human breast tumors compared to normal breast tissue [45]. In addition, higher CSN6 levels were detected in malignant follicular thyroid carcinomas compared to benign thyroid lesions or normal thyroid tissue [45]. In a transcriptomic analysis, CSN5 and CSN6 mRNA levels were shown to be higher in tumors compared to normal tissue for most myelomas as well as in breast cancer and glioblastoma patients [46].

Beyond the altered expression of the CSN and its subunits in tumors, the CSN has an established impact on several important cellular functions that often are dysregulated in tumorigenesis. The CSN is known to be involved in cell cycle and checkpoint control, regulation of proliferation and apoptosis, in the DNA damage repair pathway, and, as discussed above, in the regulation of CRLs and protein degradation. The more general role of the COP9 signalosome in cancer has recently been summarized in a couple of excellent comprehensive reviews. Therefore, we here focus on the CSN and its role in gastrointestinal cancers.

\section{Molecular Pathways Linking the CSN to Tumorigenesis}

Since many key oncogenes and tumor suppressor products such as p27, IкBa, c-Jun, p53, COP1, and $14-3-3 \sigma$ are degraded via the ubiquitin-26S-proteasome pathway and are directly or indirectly regulated by the CSN $[24,25,47-49]$, it is likely that the CSN plays a key role in cancer through several pathways.

CSN5/JAB1 is known to promote the nuclear export and subsequent degradation of the tumor suppressor p53 [50]. p53 is stabilized and activated upon DNA damage, it induces apoptosis in normal cells and is mutated in most tumors, thus incapable of properly regulating cell survival in tumor cells. Furthermore, p53 is a key effector of the DNA damage response in the cell that counteracts DNA damage generated by chemicals, reactive oxygen species, UV or ionizing radiation. Activation of the DNA damage response results in a delay or arrest of the cell cycle and in checkpoint activation and thereby protects the cell against accumulating mutations [51]. Upon UV-induced DNA damage or replication fork stress due to chemicals, the sensor kinase ATR (ataxia telangiectasia and Rad3-related protein) is activated. ATR subsequently phosphorylates and thereby activates the checkpoint kinase 1 (Chk1). Chk1 is a signal-transducing kinase that has many downstream effectors, e.g. Cdc25, p53, and Cdc45 [52]. The 9-1-1 complex (Rad9-Rad1-Hus1 complex) is loaded onto DNA after genotoxic damage and controls Chk1 phosphorylation. CSN5 was shown to interact with the 9-1-1 complex and to promote its degradation. Thus, CSN5 suppresses checkpoint signaling activation and DNA synthesis recovery after replication stress [53].

The CSN is involved in cell cycle progression at many points. First, CSN5/JAB1 was shown to regulate the CDK-inhibitor p27, promoting its nuclear export and its subsequent degradation - implying a role for the CSN in G1 progression [47]. The E3 ubiquitin ligase SCF ${ }^{\text {Skp2 }}$ controls G1/S cell cycle regulators including p27 [54]. The CSN regulates SCF ligase activity by its deNEDDylase function, but was shown to regulate Skp2 levels directly as well [55]. In addition, Skp2 forms a complex with Cul4A and DDB1 to target p27 [56]. The reduction of CSN levels causes multiple defects in the cell cycle in a subunit- and tissue-specific manner. Csn5 knockout in T-cells inhibited progression through $\mathrm{S}$ phase, but no significant effects on the G1 phase were detected [57]. T-cells with a Csn8 knockout showed defects in the reentry into the cell cycle from the G0 quiescent stage and the CSN was shown to regulate the transcription of the $G 1$ cyclins $E, D 2$ and $D 3$, and of $C D K 2$ and $C D K 4$ [58]. Furthermore, a possible direct link between the CSN and G2/M phase progression could be constituted by the interaction of CSN2 with the anaphase-promoting complex (APC)/cyclosome [59]. Additionally, the interaction between MIF and CSN5 was shown to impair the CSN's deNEDDylase function, affecting the activity of SCF ligases involved in G2/M checkpoint control [60]. Of note, the CSN has been suggested to play a key role in cell proliferation and maintenance, because the knockout of any $C s n$ subunit tested so far $(C s n 2, C s n 3, C s n 5, C s n 6, C s n 8)$ led to the death of the respective mice at a very early stage during embryonic development due to defects in cell proliferation and survival [45,58,61-63].

Schweitzer et al. discovered a functional link between the CSN and $\mathrm{NF}-\mathrm{kB}$ signaling in the cervix carcinoma cell line HeLa. Here, the CSN has been found to control the activity of $\mathrm{CRL}^{\beta \operatorname{TrCP}}$ that ubiquitinates the NF- $\kappa \mathrm{B}$ inhibitor I $\mathrm{B} \mathrm{B} \alpha$. Interestingly, the CSN also associated with USP15, thereby promoting I $\mathrm{KB} \alpha$ deubiquitination and allowing a precise regulation of NF- $\kappa B$ signaling [27]. A regulative impact of the $\mathrm{CSN}$ on NF- $\mathrm{BB}$ signaling was also shown in fibroblast cell line HEK293, where the CSN was observed to interact with the I $\mathrm{B} a$ phosphorylating IKK complex and to promote its activity [64]. NF-kB signaling has been mainly associated with inflammatory processes so far, but more and more evidence suggests this signaling pathway to play a key role in tumorigenesis as well and to be an important link of chronic inflammation and cancer [65].

The CSN shows altered expression in different human tumor entities and displays important functions in the cell, implying that the CSN could be a potential target for cancer therapy, although the identified apparent indispensible functions of CSN in cell homeostasis might also contradict this notion. Some of the CSN's functions are mediated by associated kinases as e.g. CK2 $\alpha$, PKD and IKK2 $[64,66]$. Interestingly, curcumin effectively inhibits the CSN-associated kinases [67] and is known to be anti-tumorigenic and anti-angiogenic $[68,69]$. Moreover, especially CSN's regulatory function on the cellular protein degradation machinery could be an attractive target for cancer therapy, as there are already a couple of proteasome inhibitors in 
clinical trials and in clinical use. The list encompasses Bortezomib, Carfilzomib, NPI-0052, MLN9708, CEP-18770, ONX0912, and Marizomib. Bortezomib is a peptide boronate inhibitor that binds specifically the catalytic site of the $26 \mathrm{~S}$ proteasome. It is approved for the treatment of multiple myeloma since several years and its application significantly improved the prognosis of multiple myeloma patients $[70,71]$.

\section{Role of the CSN in Hepatocellular Carcinoma and in the Liver}

Liver cancer is the fifth most common cancer in men and ranks seventh in prevalence for cancers in women. Because of its high fatality (ratio of mortality to incidence) it is the third most common cause of death from cancer worldwide [72]. Hepatocellular carcinoma (HCC) is widespread in Asia and Africa, due to frequent hepatitis B or $\mathrm{C}$ infections in these countries. In the Western world, HCC mostly results from liver fibrosis and liver cirrhosis [73]. In an array-based comparative genomic hybridization analysis of HCC patient samples, a copy number gain of chromosome 8q, encoding CSN5, was observed in $39 \%$ of the cases [39]. In parallel, high CSN5 expression was detected in these HCC samples compared to normal tissue. By immunohistochemical staining, Patil et al. identified $40 \%$ of the HCC samples to have CSN5-positive nuclei, while they did not detect CSN5 in normal hepatocytes [39]. Of note, Hsu et al. found that CSN5 overexpression in HCC tissue samples correlates with female gender and hepatitis C infection [38]. Further, CSN5 expression was monitored in developing HCC; CSN5 overexpression occurs in early stages of hepatocarcinogenesis and is significantly associated with an expression of MYC-regulated target genes [74]. This could imply that CSN5 may play a crucial role in liver cancer progression by transcriptional activation of MYC target genes. MYC serves as a transcription factor for a large variety of genes, thereby promoting proliferation, apoptosis, differentiation, metabolism, and genome stability, and is frequently overexpressed in many human cancers [75]. Association of MYC and CSN5 was described in breast cancer, where CSN5 promotes transcriptional activity of MYC, but CSN5 also destabilized MYC via the $\mathrm{SCF}^{\text {Skp2 }}$ complex [43]. Besides, a CSN5 knockdown in $\mathrm{HuH} 7 \mathrm{HCC}$ cells resulted in a significant downregulation of 83 genes that were also significantly elevated in early HCC in comparison to dysplastic nodules (HCC precursors) or cirrhotic (regenerative) nodules [74]. Supporting the hypothesis that CSN5 overexpression could drive MYC-dependent transactivation and thereby HCC progress, Panattoni et al. recently uncovered the relationship of Csn5 and Myc in the regenerating mouse liver [76]. Here, liver-specific Csn5 deletion leads to replicative stress resulting in cell cycle arrest, polyploidy and apoptosis of hepatocytes. These effects on cell behavior were phenocopied by $c-M y c$ overexpression in $C s n 5$ null hepatocytes of adult mice. Additionally, they determined complex aberrations in cell cycle progression of Csn5-deficient hepatocytes: many cells accumulated in the G2/M phase after completion of $S$ phase, but had also a tendency to replicate DNA starting from a hyperdiploid state, resulting in a large fraction of cells with $>4 \mathrm{~N}$ DNA content. These cells underwent massive, uncontrolled DNA rereplication, indicating that the CSN might be a key repressor of DNA re-replication in the course of normal cell proliferation. Together, this study revealed that hepatic Csn5, in collaboration with Myc, affects the cell cycle and DNA replication [76].

Interestingly, a reduction of the CSN5 levels by siRNA knockdown resulted in a reduced proliferation or survival rate of many human
HCC cell lines, e.g. Hep3B, HuH7, HepG2, HuH1, and PLC/PRF/5 cells $[39,77]$. Knockdown of CSN5 in HuH7 and HepG2 cells was also associated with a strong induction of apoptosis, an accumulation of G0/G1 phase cells and a decrease of cells in S phase, indicating defective cell cycle progression after reduction of CSN5 in HCC cells. In a gene expression microarray in these HCC cells, Lee et al. identified a number of genes affected by CSN5 knockdown that were also known targets of MYC or of TGF $\beta 1$ including CDK6, BRCA1, and ATF3. While genes involved in cell cycle progression, antiapoptosis, survival and metastasis (CDK6, EIF2S1, SLC2A1, ITGB1 and $L P L$ ) were down-regulated after CSN5 knockdown, the expression of genes associated with pro-apoptotic activity and tumor suppression ( $A T F 3, M P M 11, G S N$, TIMP2, FSTL3) was enhanced. Interestingly, depletion of CSN5 did not affect the protein levels of other CSN subunits, but cullin-1 hyperNEDDylation - dependent on a functional p53 gene - was induced. Moreover, CSN5 depletion was accompanied by a reduction of the cell cycle regulators cyclin D1, CDK6, and ITGB1, while the phosphorylation of the TGF $\beta$ signaling mediators SMAD2 and SMAD3, which are involved in the regulation of apoptosis, was increased. Furthermore, the knockdown of CSN5 resulted in a reduction of NF- $\kappa \mathrm{B}$ p65, in the downregulation of antiapoptotic Bcl-2 and in increased levels of pro-apoptotic Bak. Of note, loss of CSN5 resulted in a decrease of Skp2 that is part of a CRL and induces the degradation of the CDK inhibitors p21 and p27 in $\mathrm{HuH} 7$ and HepG2 cells. In parallel, an accumulation of p27 and of the tumor suppressor p53 was observed in HepG2 cells after CSN5 depletion [77].

To address CSN5 as a potential target for HCC therapy, CSN5 siRNA - encapsulated in SNALPs (stable-nucleic-acid-lipid particles) and modified with 2'-O-Methyl or with guanosine nucleosides, was given to mice with $\mathrm{HuH} 7$ cell tumors growing in their livers. The mice treated with the siRNA specific for CSN5 had smaller tumors and an improved well-being compared to control mice, indicating that CSN5 is an important player in HCC growth and might indeed be a promising target in HCC therapy [77].

Troglitazone is a peroxisome proliferator-activated receptor $\gamma$ (PPAR $\gamma$ ) ligand that exhibits anti-tumoral effects in HCC cells through inhibition of cell proliferation. It leads to an accumulation of p27 and attenuates Skp2 mRNA expression in HCC cells [78, 79]. Interestingly, treatment of HepG2 cells with troglitazone or another PPAR $\gamma$ ligand, rosiglitazone, downregulates CSN5 protein levels and mRNA expression in a dose-dependent manner by inhibition of $\beta$ catenin/Tcf4 binding to the CSN5 promotor. As expected, PPAR $\gamma$ inhibitor GW9662 as well as a PPAR knockdown reversed the troglitazone-induced inhibition of the CSN5 promotor activity. Inhibition of HepG2 cell growth after troglitazone treatment was partially rescued by ectopic CSN5 overexpression. Moreover, HepG2 cell xenografts showed a reduced volume and less blood vessels in the tumor microenvironment were detected following troglitazone treatment. In parallel, CSN5 expression and CSN5 protein levels were reduced whereas p27 levels were increased in the HepG2-xenografts, after intratumor injection of troglitazone [38].

Topoisomerase II a (topoIIa), an enzyme that loosens up the DNA helix to allow transcription, was found to be overexpressed in HCC and to be associated with chemoresistance [80]. HDAC (histone deacetylase) inhibitors, e.g. AR42 or MS-275, facilitate topoIIa proteolysis through transcriptional activation of the topollaphosphorylating enzyme CK2 $\alpha$ (casein kinase $2 \alpha$ ) by increasing the association of acetylated histone $\mathrm{H} 3$ with the $C K 2 \alpha$ promotor $[81,82]$. 
AR42 suppresses HCC tumor growth in mice [83] and enhances complex formation of CSN5 with CK2 $\alpha$ and topoIIa in human PLC5 HCC cells [82]. According to this, the knockdown of $C K 2 \alpha$, of F-box protein $F b w 7$ or of CSN5 reversed the HDAC inhibitor-induced degradation of topoIIa, whereas ectopic expression of CSN5 mimicked the suppressive effects of HDAC-inhibitors on the topoIIa levels. Phosphorylation of topoIIa by CK2 facilitates its association with the Fbw7-CSN5 complex and its subsequent degradation [82]. Together, these results indicate that high CSN5 levels facilitate topoIIa degradation and thus might counteract tumor growth.

Although most CSN/tumor research has focused on CSN5, Yu et al. studied CSN3's role in HCC and performed CSN3 knockdown experiments in HCC cell lines SMMC-7721 and Hep3B. Depletion of CSN3 resulted in a reduced proliferation rate, inhibition of anchorageindependent growth, cell cycle arrest at G0/G1 phase, inhibited DNA synthesis and enhanced apoptosis of these cells [84] - similar to the results of a CSN5 knockdown approach in $\mathrm{HuH} 7$ and $\mathrm{HepG} 2$ cells as mentioned above [77]. Yu et al. determined more human HCC samples to be CSN3-positive, especially the nuclei, compared to cirrhotic or normal tissue. In a xenograft model, the knockdown of CSN3 in SMMC-7721 HCC cells resulted in reduced tumor weight and volume [84]. Interestingly, a Csn 8 knockout in murine hepatocytes induced massive apoptosis of the cells, paralleled by a down-regulation of all other CSN subunits and an impaired deNEDDylation of cullins [85]. As also CSN8 is essential for hepatocyte survival and proliferation, the CSN might represent an interesting target for HCC therapy. Together, these findings indicate that the CSN contributes essentially to HCC tumorigenesis and one might speculate that the COP9 complex as a whole is involved.

Hepatitis is known to be associated with HCC development and $\mathrm{HBx}$ (Hepatitis B virus X protein) is a major factor in hepatitis and HCC caused by hepatitis B infections. Interestingly, CSN3, CSN4, and CSN5 were identified as $\mathrm{HBx}$-interacting proteins. In further experiments focusing on CSN5, a direct interaction of HBx and CSN5 was found to facilitate HBx-mediated AP-1 activation in the cervix carcinoma cell line HeLa [86], indicating that the CSN might be a molecular link of hepatitis B virus-induced inflammation of the liver and HCC.

In conclusion, the CSN seems to be overexpressed in HCC, it is involved in maintaining genome stability and controls cell cycle progression, and its function is closely associated with the oncogene MYC, with TGF $\beta$, and NF- $\kappa B$ signaling in the liver. Of note, HCC cells treated with CSN5/CSN3-specific siRNA showed reduced proliferation, enhanced apoptosis, inhibited anchorage-independent growth, and cell cycle arrest, and in vivo, siRNA treatment resulted in reduced tumor growth and less angiogenesis. Thus, for future HCC treatment the reduction of CSN levels might be a promising approach.

\section{Role of the CSN in Gastric Cancer}

About one million new cases of stomach cancer were estimated to have occurred in 2008, making it currently the fourth most common malignancy in the world. Gastric cancer is the second leading cause of cancer-related deaths worldwide and its development is very often associated with a Helicobacter pylori infection $[72,87]$. Recently, gene expression profiling of gastric carcinoma patient samples combined with a bioinformatic analysis revealed that CSN5 and CSN6 are significantly upregulated in gastric carcinoma. Furthermore, the transcription factors MYC and MAZ (MYC-associated zinc-finger protein) showed a similar expression profile as these CSN subunits and were significantly enriched [88].

RUNX3 (Runt-related transcription factor 3) is known to be a strong tumor suppressor in gastric cancer as well as in several other cancer entities. In gastric cancer, the expression of $R U N X 3$ is frequently lost as a result of promotor hypermethylation, and RUNX3 is often inactivated by mislocalization in the cell $[89,90]$. Interestingly, CSN5 and RUNX3 interact in SNU5 cells, a human gastric cancer cell line, and in HEK293 cells. CSN5's MPN domain and RUNX3's Runt domain were identified to be essential for this interaction. Overexpression of CSN5 resulted in lower RUNX3 levels, an effect that is inhibited by the proteasome inhibitor MG132. As expected, a knockdown of CSN5 led to an increase of RUNX3 in HEK293 cells. In parallel, CSN5 affected p21 levels - p21 is a target protein of RUNX3 and a cyclin-dependent kinase inhibitor. In addition, CSN5's MPN domain and its NES region were identified to be essential for the nuclear export and degradation of RUNX3. The nuclear export of RUNX3 is facilitated by CSN5, but is also CRM1 (chromosome region maintenance 1)-dependent. Furthermore, the CSN-associated kinase CK2 $\alpha$ was shown to support the CSN5-mediated degradation of RUNX3 [91].

MicroRNA-146a (miR-146a) is a modulator of inflammatory signals and was found upregulated in a mouse model of gastric cancer, i.e. the Gastrin knockout mouse, and in $2 / 3$ of human gastric adenocarcinomas [92]. In this study, CSN8 and CARD10 (caspase recruitment domain-containing protein 10) were identified as new targets of miR-146a. CSN8, CARD10 and IRAK1 - a known miR-146a target - all belong to signaling pathways leading to NF- $\mathrm{KB}$ activation and were all down-regulated after overexpression of miR-146a in SNU638 gastric cancer cells [92]. NF- $\kappa B$ activation is associated with inflammation-mediated gastric carcinogenesis and with gastric cancer cell migration and invasion $[93,94]$. The CSN is known to control NF$\kappa B$ activity by deubiquitination of its inhibitor I $\kappa \mathrm{B} \alpha-$ mediated by the CSN-associated deubiquitinase USP15, and by maintaining the activity of I $\mathrm{B} a$ ubiquitin ligase SCF ${ }^{\beta \operatorname{TrCP}}$ through its deNEDDylase function $[27,29,64,95]$. Crone et al. suggest the miR-146a levels to be upregulated by NF- $\kappa \mathrm{B}$ activity in a negative feedback loop and determined NF- $\kappa \mathrm{B}$ activation to be inhibited by overexpression of miRNA-146a in SNU638 cells. Furthermore, CSN2 was found to be down-regulated in this model, indicating that the CSN might be destabilized by miRNA-146a. Notably, the knockdown of CSN8, CSN2 or CSN5 in SNU638 cells inhibited GPCR-mediated activation of NF$\kappa \mathrm{B}$ comparable to the miR-146a-induced effect [92].

p57 is a CDK inhibitor and its mRNA levels were shown to be very low in gastric cancer cells $[96,97]$. It shares sequence similarity with p27 and its overexpression causes complete cell cycle arrest in G1 phase [98]. Degradation of p57 is mediated by $\mathrm{SCF}^{\text {Skp2 }}$-dependent ubiquitylation [99]. Of note, recently it was shown that $S k p 2$ depletion inhibits growth and metastasis of gastric cancer cells by inducing cell cycle arrest in the G1/S phase, paralleled by upregulation of p57 [100]. CSN6 overexpression resulted in decreased p57 levels and in an accelerated proteasomal degradation of p57 in HEK293 cells. There are hints that CSN6, p57 and Skp2 might form common complexes in the cell, and p57 degradation was shown to be Skp2-dependent [101], indicating that the CSN might associate with $\mathrm{SCF}^{\text {Skp2 }}$ E3 ligase to promote p57 ubiquitination and degradation. Thus, one might speculate that CSN(6) promotes the degradation of the CDK inhibitor p57 in gastric cancer cells to promote gastric tumor growth and metastasis. 
To date, there are just a few studies addressing CSN's potential role in gastric cancer development, but there are strong hints that the CSN is not just overexpressed in stomach cancer. It rather functionally affects the tumor suppressor RUNX3, the cell cycle regulators p21 and p57 in gastric cancer cells, and it is associated with gastric inflammation by its effect on NF- $\kappa \mathrm{B}$ signaling. Altogether, this suggests that the CSN may have an important supportive function in gastric tumorigenesis.

\section{Role of the CSN in Pancreatic Carcinoma}

Pancreatic cancer resulted in about 330,000 deaths worldwide in 2012 and thus is currently the seventh most common cause of deaths due to cancer [102]. Known risk factors for pancreatic cancer, amongst others, are smoking, obesity and diabetes [103, 104]. Pancreatic cancer often has very poor outcomes - 5-year-survival is estimated to be only $5 \%$ - due to a lack of symptoms in the early phase of the disease and thereby mostly late diagnosis, when the tumor cells have already metastasized [102].

CSN5 was shown to be overexpressed in pancreatic adenocarcinoma compared to normal pancreatic tissue [40,105]. In 27 human pancreatic adenocarcinoma cell lines, distinct high-level amplifications of chromosome $7 \mathrm{q} 22$ that encodes CSN6, were identified [106]. CSN5 overexpression was found to correlate with absent or low expression of p27 in pancreatic adenocarcinoma samples, and low p27 levels are associated with a poor prognosis for patients with pancreatic cancer $[40,105]$. In most of the tumors, the staining for CSN5 was predominantly nuclear with a weaker cytoplasmic staining [105]. This inverse correlation of CSN5 and p27 can be explained by $\operatorname{CSN}(5)$ 's role in promoting nuclear export and subsequent degradation of p27 [47,107]. In fact, enhancement of proteasomal degradation of p27 by CSN5 was seen in different pancreatic cancer cell lines, i.e. Panc-1, Mia PaCa-2, Panc-28. Additionally, a direct interaction between p27 and CSN5 was uncovered in a GST-pulldown assay and confirmed in Panc-1 and Panc-28 cells. As expected, a knockdown of CSN5 in the three mentioned pancreatic cancer cell lines resulted in an accumulation of p27 and an associated cell cycle arrest. Of note, in Panc- 28 cells, it was shown that CSN5's effect on p27 degradation was Skp2-independent [105]. p27 degradation is known to be mediated by ubiquitin E3 ligase $\mathrm{SCF}^{\text {Skp2 }}$ [108], but recently an alternative E3 ubiquitin ligase, i.e. SIAH-1 (seven in absentia homolog-1), that is regulated by CSN5, was shown to interact with p27 and to regulate its stability [109-111]. Furthermore, p8 is known to facilitate the translocation of p27 from the nucleus to the cytoplasm that is mediated by CSN5, and p8 and CSN5 were shown to directly interact [112]. p8 is a stress-inducible protein that is known to be overexpressed in stressed pancreatic tissue, in chronic pancreatitis, and in pancreatic cancer $[113,114]$.

SMAD4 is a mediator of TGF $\beta$ signaling, which regulates cell growth and differentiation, normally acts as a tumor suppressor, and was shown to be mutated or even inactivated in half of pancreatic cancers [115]. SMAD4 protein levels appear low in human pancreatic ductal adenocarcinoma [116], and SMAD4 inactivation has been suggested to be a key event during pancreatic tumorigenesis [117]. Remarkably, CSN5 promotes SMAD4 degradation in pancreatic cancer cell lines Panc-1 and AsPC-1 via SCF ${ }^{\beta T r C P}$ E3 ubiquitin ligase $[116,118]$. Point-mutated SMAD4, typically found in pancreatic adenocarcinoma, showed an increased affinity to the F-box protein $\beta \operatorname{TrCP}$; thus its degradation that is additionally promoted by high CSN5 levels, is potentially enhanced in pancreatic tissue [116].
As already discussed for HCC, the interplay between MYC and CSN5 might play a key role in pancreatic cancer as well. In Mia PaCa-2 and Panc-1 cells, knockdown of CSN5/JAB1 impaired cell proliferation and enhanced apoptosis - independent of the p53 status of the cells. These CSN5-depleted cells showed increased MYC levels and an additional depletion of $M Y C$ rescued cells from growth suppression [119].

Interestingly, Li et al. tested PEGylated curcumin, an inhibitor of the CSN-associated kinases, and asked if it inhibited cell growth of pancreatic cancer cells, and thus if it might be a potential future therapeutic for pancreatic cancer. PEG (polyethylene glycol)-ylation makes curcumin, that is known to be anti-tumorigenic, water-soluble and thereby facilitates its delivery. In this study, (PEG-)curcumin inhibited cell growth of pancreatic Panc-1, Mia PaCa-2, BxPC-3, and AsPC-1 cells in a dose-dependent manner. Additionally, the CRL targets p27 and SMAD4 were upregulated after (PEG-)curcumin treatment in Panc-1 and AsPC-1 cells, indicating that CSN's activity is inhibited. Of note, PEG-curcumin sensitized pancreatic cancer cells to gemcitabine-induced apoptosis and inhibition of cell proliferation [120]; this supports the hypothesis that the CSN and its associated kinases are promising targets in future pancreatic cancer therapy.

Together, in pancreatic tissue the CSN regulates the cell cycle by its close association with $\mathrm{p} 27$; it also affects TGF $\beta$ signaling and the tumor suppressor SMAD4, and functionally interacts with the oncogene MYC. As shown by Li et al., an inhibition of CSN activity or its associated kinases might have a therapeutic benefit for pancreatic cancer patients.

\section{Role of the CSN in Colorectal Carcinoma}

Colorectal cancer (CRC) is the third most common cancer in men and the second most prevalent one in women worldwide, resulting in about 608,000 deaths related to CRC in 2008 [72]. CRC is a very common form of cancer in the Western world due to lifestyle habits as smoking, excessive alcohol use or obesity, which are known risk factors. Diagnosis is often delayed; consequently, CRC is one of the deadliest forms of cancer.

To date, there are just a few studies that have addressed the expression and the potential role of the CSN in colorectal carcinoma. A recent study showed that $70 \%$ of the patients with colon adenocarcinoma have significantly higher CSN5 mRNA levels in the tumor tissue compared to surrounding normal tissue, and that $40 \%$ of them have significantly higher CSN6 mRNA levels in their tumors [46]. Next to this expression study, there are first hints from in vitro studies that the CSN has a functional impact on CRC cell behavior and that it might contribute to the development of the 'hallmarks' of this cancer entity. Schütz et al. showed that the reduction of CSN5 levels correlated with a reduction of CSN1 and CSN8 protein levels in SW480 CRC cells, and that the proliferation rate of different CRC cell lines (SW480, HCT116, HT29, CaCo2) was reduced after CSN5 knockdown. Surprisingly, also the rate of apoptosis after etoposide treatment was reduced by CSN5 knockdown in HCT116 cells [121]. During CRC tumorigenesis, mutations or deletions of a number of tumor suppressor genes and oncogenes accumulate [122]. CRC development is often associated with mutations of the Wnt signaling pathway. Mostly, the $A P C$ gene is mutated, but mutations in $\beta$ catenin/CTNNB1 are also observed in CRC $[123,124]$.

In normal cells, $\beta$-catenin levels are tightly regulated by a cytoplasmic destruction complex mainly consisting of APC, Axin, and 
GSK3 $\beta$, which phosphorylates $\beta$-catenin, marking it for ubiquitination and degradation by the $26 \mathrm{~S}$ proteasome. When Wnt signaling is activated by binding of a Wnt ligand to a receptor of the Frizzled family, degradation of $\beta$-catenin is inhibited, $\beta$-catenin accumulates in the cytoplasm and enters the nucleus to promote transcription of several target genes together with TCF/LEF transcription factors [125]. Activated Wnt signaling is known to be pro-proliferative and several Wnt target genes are known to promote tumorigenesis, e.g. MYC, COX-2, CD44, survivin or cyclin D1. When APC is mutated in intestinal cells and thus becomes dysfunctional, $\beta$-catenin degradation is impaired and Wnt signaling is permanently 'on', resulting, amongst other effects, in enhanced cell proliferation. Alternatively, e.g. in HCT116 cells, $\beta$-catenin itself can be mutated and its degradation becomes ineffective [124].

The CSN was shown to affect the protein levels of $\beta$-catenin in CRC cells. After knockdown of CSN5, (phospho-) $\beta$-catenin levels were reduced in HeLa and SW480 cells, indicating that the CSN might somehow 'stabilize' $\beta$-catenin. However interestingly, in SW480 cells, CSN5 was shown to also promote short-term $\beta$-catenin degradation in a cycloheximide assay [121]. Similar results were obtained with a knockdown of CSN1 that resulted in a retarded degradation of $\beta$ catenin in HeLa cells [126]. Additionally, a knockdown of CSN5 resulted in reduced $\mathrm{Wnt} / \beta$-catenin target gene expression in HCT116 cells, as shown for Axin2, MYC, CD44 and BMP4, indicating that indeed, functional Wnt signaling is affected [110]. In line with this notion, Xin et al. observed reduced COX-2 protein levels in HT29 cells after knockdown of CSN5 [127]. COX-2 is a Wnt target gene that is upregulated in CRC and contributes to its formation. It induces angiogenesis, inhibits apoptosis and promotes tumor cell invasiveness. Of note, COX-2 inhibitors are already used for CRC prevention in FAP (familial adenomatous polyposis) patients $[128,129]$.

The effect of CSN5 on $\beta$-catenin could be an effect on the canonical Wnt pathway and associated $\beta$-catenin degradation. For example, the CSN, through its deNEDDylase function, might regulate the activity of the $\mathrm{E} 3$ ligase $\mathrm{CRL}^{\beta \mathrm{TrCP}}$, which is responsible for the ubiquitination of $\beta$-catenin. Alternatively, it was shown that a knockdown of CSN1 in HeLa cells resulted in an accelerated degradation of APC, indicating that the canonical degradation of $\beta$-catenin might be impaired due to the reduced APC levels following reduction of the CSN. Furthermore, CSN-associated USP15 stabilized APC and thus might destabilize $\beta$ catenin in HeLa cells [126]. Huang et al. performed density-gradient centrifugation experiments and found that CSN3, $\beta$-catenin, and cullin-1 co-sedimented in the same fractions. By FLAG-pull-downs, they also precipitated CSN2 together with components of the $\beta$ catenin destruction complex and of $\mathrm{CRL}^{\beta \operatorname{TrCP}}$ and proposed the formation of a $\beta$-catenin-degrading super-complex containing the $26 \mathrm{~S}$ proteasome, $\mathrm{CRL}^{\beta \operatorname{TrCP}}$, the canonical $\beta$-catenin destruction complex, and the CSN [126].

On the other hand, it was recently shown that CSN5 affects SIAH-1, a key mediator of an alternative $\beta$-catenin degradation pathway [110]. SIAH-1 is induced by $\mathrm{p} 53$ and forms an alternative degradation complex for $\beta$-catenin together with SIP, SKP1, and EBI $[130,131]$, and was shown to promote $\beta$-catenin degradation in HCT116 and other cells $[110,131]$. Of note, in HCT116 CRC cells, CSN5 was shown to affect SIAH-1 protein levels, as after CSN5 knockdown SIAH-1 levels were reduced and, vice versa after CSN5 overexpression, SIAH-1 levels were elevated. CSN5 promoted SIAH-1 expression and SIAH-1 protein degradation - presumably by its deNEDDylase activity. SIAH-1, $\beta$-catenin and CSN5 potentially form common protein complexes and thus might also functionally interact as indicated by SIAH-1/CSN5-double-knockdown experiments with an analysis of Wnt target gene expression [110]. Recently, Tanaka et al. determined Sec6, a component of the exocyst complex, to interact with SIAH-1 and CSN5 in HEK293 cells. Sec6 was shown to regulate the cytoplasmic translocation of p27 and to promote its degradation [109]. Thus, the interplay between CSN(5) and SIAH-1 might be essential for the regulation of $\beta$-catenin and p27 levels, and thereby might affect cell cycle regulation and proliferation of cancer cells.

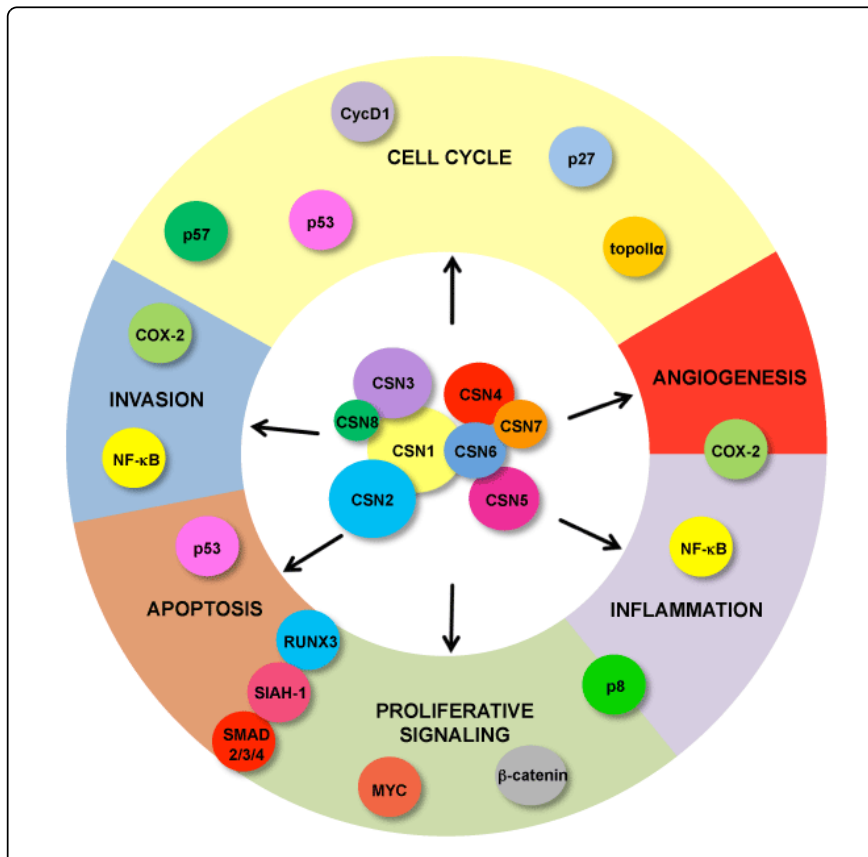

Figure 1: Proteins and their associated cellular processes affected by the COP9 signalosome in gastrointestinal cancers. Proteins depicted as circles are arranged according to their related cellular processes, divided into six categories: cell cycle, angiogenesis, inflammation, proliferative signaling, apoptosis and invasion, which are reflecting the hallmarks of cancer to a large part. Proteins located at the border of two categories were found to play a role in both cellular processes. For reasons of clarity, COX-2, NF- $\mathrm{BB}$, and $\mathrm{p} 53$, which are related to multiple processes, are depicted twice. Abbreviations: CycD1 (Cyclin D1), topoIIa (topoisomerase IIa), COX-2 (cyclooxygenase-2), NF- $\kappa B$ (nuclear factor $\kappa \mathrm{B})$, MYC ( $\mathrm{v}-$ myc avian myelocytomatosis viral oncogene homolog), SIAH-1 (seven in absentia homolog-1), SMAD2/3/4 (small mothers against decapentaplegic 2/3/4), RUNX3 (Runt-related transcription factor 3).

Hyperthermic intraperitoneal chemotherapy (HIPEC) in combination with complete cytoreductive surgery provides the only chance for long-term survival for selected patients with a variety of peritoneal neoplasms with digestive malignancies [132]. In HIPEC therapy, mitomycin $\mathrm{C}$ often is used and functions to induce DNA damage and apoptosis in tumor cells. The CSN positively influences the DNA damage response pathway that is induced by mitomycin C and counteracts chemotherapy. In a HIPEC model with HT29 cells, mitomycin C induced elevated levels of CSN1, CSN3, CSN5, and CSN8, and accelerated the deNEDDylation of cullin-1. When HT29 cells were treated with curcumin, an unspecific inhibitor of the CSN- 
Page 7 of 12

associated kinases, the mitomycin $\mathrm{C}$-induced apoptosis rate increased. In parallel, a mimic of let-7a-1, a micro-RNA, was tested to support the chemotherapeutic effects of mitomycin C. The let-7a-1 mimic treatment resulted in a reduced expression of different CSN subunits in HT29 and HeLa cells and, as a potential consequence, led to increased levels of the CDK inhibitor p27 and of the tumor suppressor p53 in HT29 cells $[133,134]$. In contrast, knockdown of CSN5 resulted in a small but significant decrease of p53 levels in SW480 cells [121].

Loda et al. correlated a lack of p27 in colorectal carcinoma to a poor survival prognosis compared to CRC patients whose tumors expressed p27 [135]. For breast and pancreatic cancer, it was shown that the expression of CSN5 negatively correlated with the levels of p27 [36, 37, 105]. According to these data, one would expect high CSN5 levels in CRC tumors to correlate with low p27 levels and with a poor prognosis. However, in a recent study no significant effect of CSN5 on p27 protein levels in SW480 CRC cells was observed [121], and to our knowledge there is no study indicating the otherwise established p27CSN5 correlation would be relevant for CRC development.

In summary, the CSN and in particular its subunit CSN5 affects many key effectors and signaling pathways in cancer cells. Some of these effects as outlined in this review article are presumably relevant in a more general sense, whereas others appear to be more specific for a certain tissue, cell type, or tumor entity.

In colorectal cancer, the CSN might be a key player as well driving tumorigenesis, because it affects signaling pathways that are crucial for CRC development, such as the Wnt signaling pathway, and is involved in $\beta$-catenin degradation. Similarly, CSN5 depletion results in reduced proliferation of CRC cells, and, as the CSN is an important player in the DNA damage response, it might be a promising therapeutic target for CRC therapy, e.g. in combination with mitomycin C chemotherapy. On the other hand, it should be kept in mind that evidence linking the CSN to CRC has mainly been in vitro so far.

\section{Conclusion}

A number of studies over the last several years have established a likely functional role of the COP9 signalosome in several gastrointestinal cancers, i.e. HCC, pancreatic cancer, gastric cancer, and CRC (summarized in table 1). There is strong evidence that the CSN plays a key role in regulating the cell cycle, proliferation, and apoptosis, and there are hints that the CSN also affects additional key processes driving tumorigenesis including angiogenesis, invasion, and chronic inflammation (Figure 1). Whether the CSN also supports the acquirement of further hallmarks of cancer, e.g. metastasis, replicative immortality, or deregulation of cellular energetics, needs to be elucidated. As outlined in this review article, the CSN affects different cellular signaling pathways such as Wnt, TGF $\beta$, and NF- $\kappa \mathrm{B}$ signaling and regulates the protein levels of important tumor suppressors. Overall, the described functions of the CSN seem to be in line with a pro-tumorigenic phenotype, as e.g. shown in many tumors after overexpression of different CSN subunits. Moreover, in preclinical in vivo models, a reduction of the CSN resulted in reduced tumor volume and less blood vessels, pointing to a potential therapeutic benefit of agents that reduce CSN protein levels and/or inhibit its functions in tumors. Thus, the CSN might be an interesting target for future therapeutic approaches for the treatment of cancer, while care needs to be taken to not interfere with its inherently crucial functions in cellular physiology.

\begin{tabular}{|c|c|c|c|c|}
\hline $\begin{array}{l}\text { Organ } / \text { tumor } \\
\text { entity }\end{array}$ & CSN subunit & Cancer (cell) type & Effect & Reference \\
\hline \multirow[t]{11}{*}{ Liver } & \multirow[t]{3}{*}{ CSN3 } & SMMC-7721 and Hep3B cells & $\begin{array}{l}\text { CSN3 promotes proliferation, anchorage-independent growth, cell } \\
\text { cycle and DNA-synthesis and counteracts apoptosis }\end{array}$ & [84] \\
\hline & & $\begin{array}{l}\text { Xenograft mouse model } \\
\text { (SMMC-7721 cells) }\end{array}$ & CSN3 knockdown reduces tumor growth and weight & [84] \\
\hline & & Human HCC tissue samples & CSN3 is overexpressed and accumulates in the nucleus & [84] \\
\hline & \multirow[t]{8}{*}{ CSN5 } & $\begin{array}{l}\text { Hep3B, HuH7, HepG2, HuH1 and } \\
\text { PLC/PRF/5 cells }\end{array}$ & CSN5 promotes cell proliferation & {$[39,77]$} \\
\hline & & HuH7 and HepG2 cells & $\begin{array}{l}\text { CSN5 facilitates cell cycle and counteracts apoptosis, decreases } \\
\text { phosphorylation of SMAD2 and SMAD3 (key mediators of } \\
\text { TGF } \beta \text { signaling) and enhances NF-KB p65 levels }\end{array}$ & [77] \\
\hline & & HuH7 cells & CSN5 siRNA encapsulated in SNALP impairs survival & [77] \\
\hline & & $\mathrm{HuH} 7$ cells & $\begin{array}{l}\text { CSN5 knockdown downregulates } 83 \text { genes shown to be elevated in } \\
\text { early HCC }\end{array}$ & [74] \\
\hline & & HepG2 cells & $\begin{array}{l}\text { PPARy ligands downregulate CSN5 protein levels and mRNA } \\
\text { expression }\end{array}$ & [38] \\
\hline & & PLC5 cells & $\begin{array}{l}\text { CSN5 promotes the HDAC inhibitor-induced degradation of topolla } \\
\text { by CRLFbw7 }\end{array}$ & [82] \\
\hline & & $\begin{array}{l}\text { Xenograft mouse model (HepG2 } \\
\text { cells) }\end{array}$ & $\begin{array}{l}\text { PPARy ligand treated tumors are smaller and have less blood } \\
\text { vessels, correlating with increased expression of CSN5 and } p 27\end{array}$ & [38] \\
\hline & & $\begin{array}{l}\text { Xenograft mouse model (HuH7 } \\
\text { cells) }\end{array}$ & $\begin{array}{l}\text { CSN5 siRNA encapsulated in SNALP decreases tumor growth and } \\
\text { improves well-being of the animals }\end{array}$ & [77] \\
\hline
\end{tabular}


Citation: Jumpertz S, Bernhagen J, Schütz AK (2015) Role of the COP9 Signalosome in Gastrointestinal Cancers. J Carcinog Mutagen 6: 210. doi:10.4172/2157-2518.1000210

Page 8 of 12

\begin{tabular}{|c|c|c|c|c|}
\hline & & \multirow[t]{3}{*}{ Human HCC tissue samples } & $\begin{array}{l}\text { Chromosome 8q, encoding CSN5, gains copy number in } 39 \% \text { of } \\
\text { samples, nuclear CSN5 levels are enhanced. }\end{array}$ & [39] \\
\hline & & & $\begin{array}{l}\text { CSN5 overexpression correlates with female gender and hepatitis C } \\
\text { viral infection }\end{array}$ & {$[38]$} \\
\hline & & & $\begin{array}{l}\text { CSN5 overexpression occurs in early stages of } \\
\text { hepatocarcinogenesis and is associated with expression of MYC- } \\
\text { regulated target genes }\end{array}$ & [74] \\
\hline \multirow[t]{6}{*}{ Stomach } & CSN2 & SNU638 cells & CSN2 knockdown inhibits GPCR-mediated NF-kB activation & [92] \\
\hline & \multirow[t]{3}{*}{ CSN5 } & SNU638 cells & CSN5 knockdown inhibits GPCR-mediated NF-KB activation & [92] \\
\hline & & SNU5 cells & CSN5 interacts with RUNX3 & {$[136]$} \\
\hline & & $\begin{array}{l}\text { Human gastric carcinoma tissue } \\
\text { samples }\end{array}$ & $\begin{array}{l}\text { Enhanced levels of CSN5 correlate with CSN6 levels and MYC and } \\
\text { MAZ expression }\end{array}$ & [88] \\
\hline & CSN6 & $\begin{array}{l}\text { Human gastric carcinoma tissue } \\
\text { samples }\end{array}$ & $\begin{array}{l}\text { Enhanced levels of CSN6 correlate with CSN5 levels and MYC and } \\
\text { MAZ expression }\end{array}$ & [88] \\
\hline & CSN8 & SNU638 cells & Overexpression of miRNA-146a downregulates CSN8 and CARD10 & [92] \\
\hline \multirow[t]{12}{*}{ Pancreas } & \multirow[t]{11}{*}{ CSN5 } & $\begin{array}{l}\text { Mia PaCa-2, Panc-28 and Panc-1 } \\
\text { cells }\end{array}$ & CSN5 facilitates $p 27$ degradation & {$[105]$} \\
\hline & & Panc- 28 and Panc- 1 cells & CSN5 interacts with p27 & [105] \\
\hline & & Mia PaCa-2 and Panc-28 cells & CSN5 promotes cell cycle progression & {$[105]$} \\
\hline & & Panc-28 cells & CSN5-dependent degradation of p27 might be Skp2-independent & [105] \\
\hline & & Panc-1 and AsPC-1 cells & CSN5 promotes SMAD4 degradation via SCF ${ }^{\beta T r C P}$ & {$[116,118]$} \\
\hline & & Mia PaCa-2 and Panc-1 cells & CSN5 promotes cell proliferation and inhibits apoptosis via MYC & {$[119]$} \\
\hline & & Panc-1 and AsPC-1 cells & $\begin{array}{l}\text { PEGylated curcumin (CSN-associated kinase inhibitor) promotes } \\
\text { apoptosis following gemcitabine treatment, inhibits cell growth via } \\
\text { decelerating cell proliferation and increases levels of CSN5 } \\
\text { degradation targets p27 and SMAD4 }\end{array}$ & {$[120]$} \\
\hline & & Mia PaCa-2 cells & $\begin{array}{l}\text { PEGylated curcumin inhibits cell growth via decelerating } \\
\text { proliferation }\end{array}$ & {$[120]$} \\
\hline & & BxPC-3 cells & PEGylated curcumin inhibits cell growth & {$[120]$} \\
\hline & & $\begin{array}{l}\text { Pancreatic adenocarcinoma tissue } \\
\text { samples }\end{array}$ & $\begin{array}{l}\text { CSN5 is overexpressed in tumors, mainly in the cytoplasm; patients } \\
\text { with p27-positive tumors had a significant better prognosis than } \\
\text { those with p27-negative tumors, and p27 localized exclusively in the } \\
\text { nucleus further improved their prognosis }\end{array}$ & {$[40]$} \\
\hline & & $\begin{array}{l}\text { Pancreatic adenocarcinoma tissue } \\
\text { samples }\end{array}$ & $\begin{array}{l}\text { CSN5 is overexpressed and inversely correlates with p27 levels; in } \\
72 \% \text { of the tumors predominant nuclear staining for CSN5; tumors } \\
\text { with predominant cytoplasmic CSN5-staining were all p27-negative } \\
\text { and had a higher proliferation index than cells with predominant } \\
\text { nuclear CSN5-staining }\end{array}$ & {$[105]$} \\
\hline & CSN6 & $\begin{array}{l}\text { Pancreatic adenocarcinoma tissue } \\
\text { samples }\end{array}$ & High-level amplifications of chromosome 7q22, encoding CSN6 & {$[106]$} \\
\hline \multirow[t]{4}{*}{ Colon } & \multirow[t]{4}{*}{ CSN5 } & SW480 cells & $\begin{array}{l}\text { CSN5 knockdown reduces (phospho-) B-catenin, CSN1, CSN8, and } \\
\text { p53 protein levels, and decelerates proliferation }\end{array}$ & {$[121]$} \\
\hline & & HCT116 cells & $\begin{array}{l}\text { CSN5 promotes apoptosis after etoposide treatment and enhances } \\
\text { proliferation }\end{array}$ & {$[121]$} \\
\hline & & HCT116 cells & $\begin{array}{l}\text { CSN5 promotes expression of Wnt/ } \beta \text {-catenin target genes and of } \\
\text { SIAH-1, but also supports SIAH-1 degradation, depending on } \\
\text { Cullin } 1-N E D D y l a t i o n\end{array}$ & {$[110]$} \\
\hline & & HT29 cells & CSN5 knockdown affects COX-2 protein levels & {$[127]$} \\
\hline
\end{tabular}




\begin{tabular}{|l|l|l|l|l|}
\hline & HT29 cells & CSN5 promotes proliferation & [121] \\
\cline { 3 - 5 } & CaCo2 cells & CSN5 promotes proliferation & [121] \\
\cline { 2 - 5 } & $\begin{array}{l}\text { Colon adenocarcinoma tissue } \\
\text { samples }\end{array}$ & $\begin{array}{l}\text { Higher CSN5 mRNA levels in 70\% of the tumor samples compared } \\
\text { to normal tissue }\end{array}$ & [46] \\
\cline { 2 - 5 } & $\begin{array}{l}\text { Colon adenocarcinoma tissue } \\
\text { samples }\end{array}$ & $\begin{array}{l}\text { Higher CSN6 mRNA levels in 40\% of the tumor samples compared } \\
\text { to normal tissue }\end{array}$ & [46] \\
\hline
\end{tabular}

Table 1: Summary of functional evidence for a role of the CSN in gastrointestinal tumorigenesis.

\section{Acknowledgements}

We are indebted to numerous colleagues for inspiring and helpful discussions and apologize to the many colleagues and scientists in the field whose work we were not able to cite due to space constraints.

\section{Financial support}

This work was funded by a START-Up grant of the DFG excellence program of RWTH Aachen University (grant 351400) and a START grant of RWTH Aachen University Medical School (grant 690644) to A.K.S., by the START consortium grant 69605-5/project P6 of RWTH Aachen University Medical School to J.B., and by the IZKF Aachen grant SP/O-3 to J.B..

\section{References:}

1. Chamovitz DA, Wei N, Osterlund MT, von Arnim AG, Staub JM, et al. (1996) The COP9 complex, a novel multisubunit nuclear regulator involved in light control of a plant developmental switch. Cell 86: 115-121.

2. Seeger M, Kraft R, Ferrell K, Bech-Otschir D, Dumdey R, et al. (1998) A novel protein complex involved in signal transduction possessing similarities to $26 \mathrm{~S}$ proteasome subunits. FASEB J 12: 469-78.

3. Wei N, Deng XW (1998) Characterization and purification of the mammalian COP9 complex, a conserved nuclear regulator initially identified as a repressor of photomorphogenesis in higher plants. Photochem Photobiol 68: 237-241.

4. Claret FX, Hibi M, Dhut S, Toda T, Karin M (1996) A new group of conserved coactivators that increase the specificity of AP-1 transcription factors. Nature 383: 453-457.

5. Busch S, Eckert SE, Krappmann S, Braus GH (2003) The COP9 signalosome is an essential regulator of development in the filamentous fungus Aspergillus nidulans. Mol Microbiol 49: 717-730.

6. Maytal-Kivity V, Pick E, Piran R, Hofmann K, Glickman MH (2003) The COP9 signalosome-like complex in S. cerevisiae and links to other PCI complexes. Int J Biochem Cell Biol 35: 706-715.

7. Mundt KE, Porte J, Murray JM, Brikos C, Christensen PU, et al. (1999) The COP9/signalosome complex is conserved in fission yeast and has a role in S phase. Curr Biol 9: 1427-1430.

8. Wee S, Hetfeld B, Dubiel W, Wolf DA (2002) Conservation of the COP9/ signalosome in budding yeast. BMC Genet 3: 15 .

9. Luke-Glaser S, Roy M, Larsen B, Le Bihan T, Metalnikov P, et al. (2007) CIF-1, a shared subunit of the COP9/signalosome and eukaryotic initiation factor 3 complexes, regulates MEL-26 levels in the Caenorhabditis elegans embryo. Mol Cell Biol 27: 4526-4540.

10. Freilich S, Oron E, Kapp Y, Nevo-Caspi Y, Orgad S, et al. (1999) The COP9 signalosome is essential for development of Drosophila melanogaster. Curr Biol 9: 1187-1190.

11. Deng XW, Dubiel W, Wei N, Hofmann K, Mundt K, et al. (2000) Unified nomenclature for the COP9 signalosome and its subunits: an essential regulator of development. Trends Genet 16: 202-203.
12. Kato JY, Yoneda-Kato N (2009) Mammalian COP9 signalosome. Genes Cells 14: 1209-1225.

13. Sharon M, Mao H, Boeri Erba E, Stephens E, Zheng N, et al. (2009) Symmetrical modularity of the COP9 signalosome complex suggests its multifunctionality. Structure 17: 31-40.

14. Fukumoto A, Tomoda K, Kubota M, Kato JY, Yoneda-Kato N (2005) Small Jab1-containing subcomplex is regulated in an anchorage- and cell cycle-dependent manner, which is abrogated by ras transformation. FEBS Lett 579: 1047-1054.

15. Hofmann K, Bucher P (1998) The PCI domain: a common theme in three multiprotein complexes. Trends Biochem Sci 23: 204-205.

16. Wei N, Serino G, Deng XW (2008) The COP9 signalosome: more than a protease. Trends Biochem Sci 33: 592-600.

17. Lingaraju GM, Bunker RD, Cavadini S, Hess D, Hassiepen U, et al. (2014) Crystal structure of the human COP9 signalosome. Nature 512: 161-165.

18. Ambroggio XI, Rees DC, Deshaies RJ (2004) JAMM: a metalloproteaselike zinc site in the proteasome and signalosome. PLoS Biol 2: E2.

19. Cope GA, Suh GS, Aravind L, Schwarz SE, Zipursky SL, et al. (2002) Role of predicted metalloprotease motif of Jab1/Csn5 in cleavage of Nedd8 from Cul1. Science 298: 608-611.

20. Lyapina S, Cope G, Shevchenko A, Serino G, Tsuge T, et al. (2001) Promotion of NEDD-CUL1 conjugate cleavage by COP9 signalosome. Science 292: 1382-1385.

21. Petroski MD, Deshaies RJ (2005) Function and regulation of cullin-RING ubiquitin ligases. Nat Rev Mol Cell Biol 6: 9-20.

22. Saha A, Deshaies RJ (2008) Multimodal activation of the ubiquitin ligase SCF by Nedd8 conjugation. Mol Cell 32: 21-31.

23. Read MA, Brownell JE, Gladysheva TB, Hottelet M, Parent LA, et al. (2000) Nedd8 modification of cul-1 activates SCF(beta(TrCP))dependent ubiquitination of IkappaBalpha. Mol Cell Biol 20: 2326-2333.

24. Zhang XC, Chen J, Su CH, Yang HY, Lee MH (2008) Roles for CSN5 in control of p53/MDM2 activities. J Cell Biochem 103: 1219-1230.

25. Choi HH, Gully C, Su CH, Velazquez-Torres G, Chou PC, et al. (2011) COP9 signalosome subunit 6 stabilizes COP1, which functions as an E3 ubiquitin ligase for 14-3-3sigma. Oncogene 30: 4791-4801.

26. Bianchi E, Denti S, Catena R, Rossetti G, Polo S, et al. (2003) Characterization of human constitutive photomorphogenesis protein 1 , a RING finger ubiquitin ligase that interacts with Jun transcription factors and modulates their transcriptional activity. J Biol Chem 278: 19682-19690.

27. Schweitzer K, Bozko PM, Dubiel W, Naumann M (2007) CSN controls NF-kappaB by deubiquitinylation of IkappaBalpha. EMBO J 26: 1532-1541.

28. Azuma Y, Takada M, Maeda M, Kioka N, Ueda K (2009) The COP9 signalosome controls ubiquitinylation of ABCA1. Biochem Biophys Res Commun 382: 145-148.

29. Asare Y, Shagdarsuren E, Schmid JA, Tilstam PV, Grommes J, et al. (2013) Endothelial CSN5 impairs NF-kB activation and monocyte adhesion to endothelial cells and is highly expressed in human atherosclerotic lesions. Thromb Haemost 110: 141-152. 
30. Kinoshita SM, Krutzik PO, Nolan GP (2012) COP9 signalosome component JAB1/CSN5 is necessary for T cell signaling through LFA-1 and HIV-1 replication. PLoS One 7: e41725.

31. Su H, Li J, Menon S, Liu J, Kumarapeli AR, et al. (2011) Perturbation of cullin deneddylation via conditional Csn8 ablation impairs the ubiquitinproteasome system and causes cardiomyocyte necrosis and dilated cardiomyopathy in mice. Circ Res 108: 40-50.

32. Deng Z, Pardi R, Cheadle W, Xiang X, Zhang S, et al. (2011) Plant homologue constitutive photomorphogenesis 9 (COP9) signalosome subunit CSN5 regulates innate immune responses in macrophages. Blood 117: 4796-4804

33. Shen L, Tsuchida R, Miyauchi J, Saeki M, Honna T, et al. (2000) Differentiation-associated expression and intracellular localization of cyclin-dependent kinase inhibitor p27KIP1 and c-Jun co-activator JAB1 in neuroblastoma. Int J Oncol 17: 749-54.

34. Sui L, Dong Y, Ohno M, Watanabe Y, Sugimoto K, et al. (2001) Jab1 expression is associated with inverse expression of p27(kip1) and poor prognosis in epithelial ovarian tumors. Clin Cancer Res 7: 4130-4135.

35. Sui L, Dong Y, Watanabe Y, Yamaguchi F, Sugimoto K, et al. (2006) Clinical significance of Skp2 expression, alone and combined with Jab1 and p27 in epithelial ovarian tumors. Oncol Rep 15: 765-771.

36. Esteva FJ, Sahin AA, Rassidakis GZ, Yuan LX, Smith TL, et al. (2003) Jun activation domain binding protein 1 expression is associated with low p27(Kip1)levels in node-negative breast cancer. Clin Cancer Res 9: 5652-5659.

37. Kouvaraki MA, Rassidakis GZ, Tian L, Kumar R, Kittas C, et al. (2003) Jun activation domain-binding protein 1 expression in breast cancer inversely correlates with the cell cycle inhibitor p27(Kip1). Cancer Res 63: 2977-2981.

38. Hsu MC, Huang CC, Chang HC, Hu TH, Hung WC (2008) Overexpression of Jab1 in hepatocellular carcinoma and its inhibition by peroxisome proliferator-activated receptor\{gamma\} ligands in vitro and in vivo. Clin Cancer Res 14: 4045-4052.

39. Patil MA, Gutgemann I, Zhang J, Ho C, Cheung ST, et al. (2005) Arraybased comparative genomic hybridization reveals recurrent chromosomal aberrations and Jab1 as a potential target for 8q gain in hepatocellular carcinoma. Carcinogenesis 26: 2050-2057.

40. Fukumoto A, Ikeda N, Sho M, Tomoda K, Kanehiro H, et al. (2004) Prognostic significance of localized p27Kip1 and potential role of Jab1/ CSN5 in pancreatic cancer. Oncol Rep 11: 277-284.

41. Goto A, Niki T, Moriyama S, Funata N, Moriyama H, et al. (2004) Immunohistochemical study of Skp2 and Jab1, two key molecules in the degradation of P27, in lung adenocarcinoma. Pathol Int 54: 675-681.

42. Ito Y, Yoshida H, Matsuzuka F, Matsuura N, Nakamura Y, et al. (2003) Jun activation domain-binding protein 1 expression in malignant lymphoma of the thyroid: its linkage to degree of malignancy and p27 expression. Anticancer Res 23: 4121-4125.

43. Adler AS, Lin M, Horlings H, Nuyten DS, van de Vijver MJ, et al. (2006) Genetic regulators of large-scale transcriptional signatures in cancer. Nat Genet 38: 421-430.

44. Bhansali M, Shemshedini L (2014) COP9 subunits 4 and 5 target soluble guanylyl cyclase $\alpha 1$ and p53 in prostate cancer cells. Mol Endocrinol 28: 834-845.

45. Zhao R, Yeung SC, Chen J, Iwakuma T, Su CH, et al. (2011) Subunit 6 of the COP9 signalosome promotes tumorigenesis in mice through stabilization of MDM2 and is upregulated in human cancers. J Clin Invest 121: 851-865

46. Lee MH, Zhao R, Phan L, Yeung SC (2011) Roles of COP9 signalosome in cancer. Cell Cycle 10: 3057-3066.

47. Tomoda K, Kubota Y, Kato J (1999) Degradation of the cyclindependent-kinase inhibitor p27Kip1 is instigated by Jab1. Nature 398: 160-165.

48. Naumann M, Bech-Otschir D, Huang X, Ferrell K, Dubiel W (1999) COP9 signalosome-directed c-Jun activation/stabilization is independent of JNK. J Biol Chem 274: 35297-35300.
49. Bech-Otschir D, Kraft R, Huang X, Henklein P, Kapelari B, et al. (2001) COP9 signalosome-specific phosphorylation targets p53 to degradation by the ubiquitin system. EMBO J 20: 1630-1639.

50. Oh W, Lee EW, Sung YH, Yang MR, Ghim J, et al. (2006) Jab1 induces the cytoplasmic localization and degradation of $\mathrm{p} 53$ in coordination with Hdm2. J Biol Chem 281: 17457-17465.

51. Brady CA, Attardi LD (2010) p53 at a glance. J Cell Sci 123: 2527-2532.

52. Smith J, Tho LM, Xu N, Gillespie DA (2010) The ATM-Chk2 and ATRChk1 pathways in DNA damage signaling and cancer. Adv Cancer Res 108: 73-112.

53. Huang J, Yuan H, Lu C, Liu X, Cao X, et al. (2007) Jab1 mediates protein degradation of the Rad9-Rad1-Hus1 checkpoint complex. J Mol Biol 371: 514-527.

54. Yang X, Menon S, Lykke-Andersen K, Tsuge T, Di Xiao, et al. (2002) The COP9 signalosome inhibits p27(kip1) degradation and impedes G1-S phase progression via deneddylation of SCF Cul1. Curr Biol 12: 667-672.

55. Denti S, Fernandez-Sanchez ME, Rogge L, Bianchi E (2006) The COP9 signalosome regulates Skp2 levels and proliferation of human cells. J Biol Chem 281: 32188-32196.

56. Bondar T, Kalinina A, Khair L, Kopanja D, Nag A, et al. (2006) Cul4A and DDB1 associate with Skp2 to target p27Kip1 for proteolysis involving the COP9 signalosome. Mol Cell Biol 26: 2531-2539.

57. Panattoni M, Sanvito F, Basso V, Doglioni C, Casorati G, et al. (2008) Targeted inactivation of the COP9 signalosome impairs multiple stages of T cell development. J Exp Med 205: 465-477.

58. Menon S, Chi H, Zhang H, Deng XW, Flavell RA, et al. (2007) COP9 signalosome subunit 8 is essential for peripheral $\mathrm{T}$ cell homeostasis and antigen receptor-induced entry into the cell cycle from quiescence. Nat Immunol 8: 1236-1245.

59. Kob R, Kelm J, Posorski N, Baniahmad A, von Eggeling F, et al. (2009) Regulation of the anaphase-promoting complex by the COP9 signalosome. Cell Cycle 8: 2041-2049.

60. Fingerle-Rowson G, Petrenko O (2007) MIF coordinates the cell cycle with DNA damage checkpoints. Lessons from knockout mouse models. Cell Div 2: 22.

61. Lykke-Andersen K, Schaefer L, Menon S, Deng XW, Miller JB, et al. (2003) Disruption of the COP9 signalosome Csn2 subunit in mice causes deficient cell proliferation, accumulation of p53 and cyclin E, and early embryonic death. Mol Cell Biol 23: 6790-6797.

62. Yan J, Walz K, Nakamura H, Carattini-Rivera S, Zhao Q, et al. (2003) COP9 signalosome subunit 3 is essential for maintenance of cell proliferation in the mouse embryonic epiblast. Mol Cell Biol 23: 6798-6808.

63. Tomoda K, Yoneda-Kato N, Fukumoto A, Yamanaka S, Kato JY (2004) Multiple functions of Jab1 are required for early embryonic development and growth potential in mice. J Biol Chem 279: 43013-43018.

64. Orel L, Neumeier H, Hochrainer K, Binder BR, Schmid JA (2010) Crosstalk between the NF-kappaB activating IKK-complex and the CSN signalosome. J Cell Mol Med 14: 1555-1568.

65. Karin M (2009) NF-kappaB as a critical link between inflammation and cancer. Cold Spring Harb Perspect Biol 1: a000141.

66. Uhle S, Medalia O, Waldron R, Dumdey R, Henklein P, et al. (2003) Protein kinase CK2 and protein kinase D are associated with the COP9 signalosome. EMBO J 22: 1302-1312.

67. Henke W, Ferrell K, Bech-Otschir D, Seeger M, Schade R, et al. (1999) Comparison of human COP9 signalsome and 26S proteasome lid'. Mol Biol Rep 26: 29-34.

68. Huang MT, Ma W, Lu YP, Chang RL, Fisher C, et al. (1995) Effects of curcumin, demethoxycurcumin, bisdemethoxycurcumin and tetrahydrocurcumin on 12-O-tetradecanoylphorbol-13-acetate-induced tumor promotion. Carcinogenesis 16: 2493-2497.

69. Arbiser JL, Klauber N, Rohan R, van Leeuwen R, Huang MT, et al. (1998) Curcumin is an in vivo inhibitor of angiogenesis. Mol Med 4: 376-383.

70. Crawford LJ, Walker B, Irvine AE (2011) Proteasome inhibitors in cancer therapy. J Cell Commun Signal 5: 101-110. 
71. Moreau P, Richardson PG, Cavo M, Orlowski RZ, San Miguel JF, et al. (2012) Proteasome inhibitors in multiple myeloma: 10 years later. Blood 120: 947-959.

72. Ferlay J, Shin HR, Bray F, Forman D, Mathers C, et al. (2010) Estimates of worldwide burden of cancer in 2008: GLOBOCAN 2008. Int J Cancer 127: 2893-2917.

73. Kirstein MM, Vogel A (2014) The pathogenesis of hepatocellular carcinoma. Dig Dis 32: 545-553.

74. Kaposi-Novak P, Libbrecht L, Woo HG, Lee YH, Sears NC, et al. (2009) Central role of $\mathrm{c}-\mathrm{Myc}$ during malignant conversion in human hepatocarcinogenesis. Cancer Res 69: 2775-2782.

75. Li B, Simon MC (2013) Molecular Pathways: Targeting MYC-induced metabolic reprogramming and oncogenic stress in cancer. Clin Cancer Res 19: 5835-5841.

76. Panattoni M, Maiorino L, Lukacs A, Zentilin L, Mazza D, et al. (2014) The COP9 signalosome is a repressor of replicative stress responses and polyploidization in the regenerating liver. Hepatology 59: 2331-2343.

77. Lee YH, Judge AD, Seo D, Kitade M, Gómez-Quiroz LE, et al. (2011) Molecular targeting of CSN5 in human hepatocellular carcinoma: a mechanism of therapeutic response. Oncogene 30: 4175-4184.

78. Koga H, Harada M, Ohtsubo M, Shishido S, Kumemura H, et al. (2003) Troglitazone induces p27Kip1-associated cell-cycle arrest through downregulating Skp2 in human hepatoma cells. Hepatology 37: 1086-1096.

79. Koga H, Sakisaka S, Harada M, Takagi T, Hanada S, et al. (2001) Involvement of p21(WAF1/Cip1), p27(Kip1), and p18(INK4c) in troglitazone-induced cell-cycle arrest in human hepatoma cell lines. Hepatology 33: 1087-1097.

80. Wong N, Yeo W, Wong WL, Wong NL, Chan KY, et al. (2009) TOP2A overexpression in hepatocellular carcinoma correlates with early age onset, shorter patients survival and chemoresistance. Int J Cancer 124: 644-652.

81. Zhang A, Lyu YL, Lin CP, Zhou N, Azarova AM, et al. (2006) A protease pathway for the repair of topoisomerase II-DNA covalent complexes. J Biol Chem 281: 35997-36003.

82. Chen MC, Chen CH, Chuang HC, Kulp SK, Teng CM, et al. (2011) Novel mechanism by which histone deacetylase inhibitors facilitate topoisomerase II alpha degradation in hepatocellular carcinoma cells. Hepatology 53: 148-159.

83. Lu YS, Kashida Y, Kulp SK, Wang YC, Wang D, et al. (2007) Efficacy of a novel histone deacetylase inhibitor in murine models of hepatocellular carcinoma. Hepatology 46: 1119-1130.

84. Yu YS, Tang ZH, Pan QC, Chen XH, Liu XN, et al. (2012) Inhibition of Csn3 expression induces growth arrest and apoptosis of hepatocellular carcinoma cells. Cancer Chemother Pharmacol 69: 1173-1180.

85. Lei D, Li F, Su H, Tian Z, Ye B, et al. (2011) COP9 signalosome subunit 8 is required for postnatal hepatocyte survival and effective proliferation. Cell Death Differ 18: 259-270.

86. Tanaka Y, Kanai F, Ichimura T, Tateishi K, Asaoka Y, et al. (2006) The hepatitis $\mathrm{B}$ virus $\mathrm{X}$ protein enhances AP-1 activation through interaction with Jab1. Oncogene 25: 633-642.

87. Parsonnet J, Friedman GD, Vandersteen DP, Chang Y, Vogelman JH, et al. (1991) Helicobacter pylori infection and the risk of gastric carcinoma. N Engl J Med 325: 1127-1131.

88. Liu N, Liu X, Zhou N, Wu Q, Zhou L, et al. (2014) Gene expression profiling and bioinformatics analysis of gastric carcinoma. Exp Mol Pathol 96: 361-366.

89. Oshimo Y, Oue N, Mitani Y, Nakayama H, Kitadai Y, et al. (2004) Frequent loss of RUNX3 expression by promoter hypermethylation in gastric carcinoma. Pathobiology 71: 137-143.

90. Ito K, Liu Q, Salto-Tellez M, Yano T, Tada K, et al. (2005) RUNX3, a novel tumor suppressor, is frequently inactivated in gastric cancer by protein mislocalization. Cancer Res 65: 7743-7750.

91. Kim JH, Choi JK, Cinghu S, Jang JW, Lee YS, et al. (2009) Jab1/CSN5 induces the cytoplasmic localization and degradation of RUNX3. J Cell Biochem 107: 557-565.
92. Crone SG, Jacobsen A, Federspiel B, Bardram L, Krogh A, et al. (2012) microRNA-146a inhibits $G$ protein-coupled receptor-mediated activation of NF- $\kappa \mathrm{B}$ by targeting CARD10 and COPS8 in gastric cancer. Mol Cancer 11: 71.

93. Wu WK, Cho CH, Lee CW, Fan D, Wu K, et al. (2010) Dysregulation of cellular signaling in gastric cancer. Cancer Lett 295: 144-153.

94. Murray D, Horgan G, Macmathuna P, Doran P (2008) NET1-mediated RhoA activation facilitates lysophosphatidic acid-induced cell migration and invasion in gastric cancer. Br J Cancer 99: 1322-1329.

95. Winston JT, Strack P, Beer-Romero P, Chu CY, Elledge SJ, et al. (1999) The SCFbeta-TRCP-ubiquitin ligase complex associates specifically with phosphorylated destruction motifs in IkappaBalpha and beta-catenin and stimulates IkappaBalpha ubiquitination in vitro. Genes Dev 13: 270-283.

96. Shin JY, Kim HS, Lee KS, Kim J, Park JB, et al. (2000) Mutation and expression of the p27KIP1 and p57KIP2 genes in human gastric cancer. Exp Mol Med 32: 79-83.

97. Lee MH, Yang HY (2001) Negative regulators of cyclin-dependent kinases and their roles in cancers. Cell Mol Life Sci 58: 1907-1922.

98. Lee MH, Reynisdóttir I, Massagué J (1995) Cloning of p57KIP2, a cyclindependent kinase inhibitor with unique domain structure and tissue distribution. Genes Dev 9: 639-649.

99. Kamura T, Hara T, Kotoshiba S, Yada M, Ishida N, et al. (2003) Degradation of p57Kip2 mediated by SCFSkp2-dependent ubiquitylation. Proc Natl Acad Sci U S A 100: 10231-10236.

100. Wei Z, Jiang X, Liu F, Qiao H, Zhou B, et al. (2013) Downregulation of Skp2 inhibits the growth and metastasis of gastric cancer cells in vitro and in vivo. Tumour Biol 34: 181-192.

101. Chen B, Zhao R, Su CH, Linan M, Tseng C, et al. (2012) CDK inhibitor p57 (Kip2) is negatively regulated by COP9 signalosome subunit 6 . Cell Cycle 11: 4633-4641.

102. World-Health-Organization (2014) World Cancer Report 2014

103. Iodice S, Gandini S, Maisonneuve P, Lowenfels AB (2008) Tobacco and the risk of pancreatic cancer: a review and meta-analysis. Langenbecks Arch Surg 393: 535-545.

104. Bond-Smith G, Banga N, Hammond TM, Imber CJ (2012) Pancreatic adenocarcinoma. BMJ 344: e2476.

105. Kouvaraki MA, Korapati AL, Rassidakis GZ, Tian L, Zhang Q, et al. (2006) Potential role of Jun activation domain-binding protein 1 as a negative regulator of p27kip1 in pancreatic adenocarcinoma. Cancer Res 66: 8581-8589.

106. Solinas-Toldo S, Wallrapp C, Müller-Pillasch F, Bentz M, Gress T, et al. (1996) Mapping of chromosomal imbalances in pancreatic carcinoma by comparative genomic hybridization. Cancer Res 56: 3803-3807.

107. Tomoda K, Kubota Y, Arata Y, Mori S, Maeda M, et al. (2002) The cytoplasmic shuttling and subsequent degradation of p27Kip1 mediated by Jab1/CSN5 and the COP9 signalosome complex. J Biol Chem 277: 2302-2310.

108. Carrano AC, Eytan E, Hershko A, Pagano M (1999) SKP2 is required for ubiquitin-mediated degradation of the CDK inhibitor p27. Nat Cell Biol 1: 193-199.

109. Tanaka T, Iino M (2014) Sec6 regulated cytoplasmic translocation and degradation of p27 via interactions with Jab1 and Siah1. Cell Signal 26: 2071-2085.

110. Jumpertz S, Hennes T, Asare Y, Vervoorts J, Bernhagen J, et al. (2014) The $\beta$-catenin E3 ubiquitin ligase SIAH-1 is regulated by CSN5/JAB1 in CRC cells. Cell Signal 26: 2051-2059.

111. Nagano Y, Fukushima T, Okemoto K, Tanaka K, Bowtell DD, et al. (2011) Siah1/SIP regulates p27(kip1) stability and cell migration under metabolic stress. Cell Cycle 10: 2592-2602.

112. Malicet C, Hoffmeister A, Moreno S, Closa D, Dagorn JC, et al. (2006) Interaction of the stress protein p8 with Jab1 is required for Jab1dependent p27 nuclear-to-cytoplasm translocation. Biochem Biophys Res Commun 339: 284-289.

113. Su SB, Motoo Y, Iovanna JL, Xie MJ, Mouri H, et al. (2001) Expression of p8 in human pancreatic cancer. Clin Cancer Res 7: 309-313. 
Citation: Jumpertz S, Bernhagen J, Schütz AK (2015) Role of the COP9 Signalosome in Gastrointestinal Cancers. J Carcinog Mutagen 6: 210. doi:10.4172/2157-2518.1000210

Page 12 of 12

114. Savkovic V, Gaiser S, Iovanna JL, Bödeker H (2004) The stress response of the exocrine pancreas. Dig Dis 22: 239-246.

115. Singh P, Wig JD, Srinivasan R (2011) The Smad family and its role in pancreatic cancer. Indian J Cancer 48: 351-360.

116. Wan M, Huang J, Jhala NC, Tytler EM, Yang L, et al. (2005) SCF(betaTrCP1) controls Smad4 protein stability in pancreatic cancer cells. Am J Pathol 166: 1379-1392.

117. Cowan RW, Maitra A (2014) Genetic progression of pancreatic cancer. Cancer J 20: 80-84.

118. Wan M, Cao X, Wu Y, Bai S, Wu L, et al. (2002) Jab1 antagonizes TGFbeta signaling by inducing Smad4 degradation. EMBO Rep 3: 171-176.

119. Fukumoto A, Tomoda K, Yoneda-Kato N, Nakajima Y, Kato JY (2006) Depletion of Jab1 inhibits proliferation of pancreatic cancer cell lines. FEBS Lett 580: 5836-5844.

120. Li J, Wang Y, Yang C, Wang P, Oelschlager DK, et al. (2009) Polyethylene glycosylated curcumin conjugate inhibits pancreatic cancer cell growth through inactivation of Jab1. Mol Pharmacol 76: 81-90.

121. Schütz AK, Hennes T, Jumpertz S, Fuchs S, Bernhagen J (2012) Role of CSN5/JAB1 in Wnt/ $\beta$-catenin activation in colorectal cancer cells. FEBS Lett 586: 1645-1651.

122. Phelps RA, Chidester S, Dehghanizadeh S, Phelps J, Sandoval IT, et al. (2009) A two-step model for colon adenoma initiation and progression caused by APC loss. Cell 137: 623-634.

123. Kinzler KW, Vogelstein B (1996) Lessons from hereditary colorecta cancer. Cell 87: 159-170.

124. Ilyas M, Tomlinson IP, Rowan A, Pignatelli M, Bodmer WF (1997) Betacatenin mutations in cell lines established from human colorectal cancers. Proc Natl Acad Sci U S A 94: 10330-10334.

125. Clevers H, Nusse R (2012) Wnt/ $\beta$-catenin signaling and disease. Cell 149: 1192-1205.

126. Huang X, Langelotz C, Hetfeld-Pechoc BK, Schwenk W, Dubiel W (2009) The COP9 signalosome mediates beta-catenin degradation by deneddylation and blocks adenomatous polyposis coli destruction via USP15. J Mol Biol 391: 691-702.

127. Xin D, Rendon BE, Zhao M, Winner M, McGhee Coleman A, et al. (2010) The MIF homologue D-dopachrome tautomerase promotes COX-2 expression through $\beta$-catenin-dependent and -independent mechanisms. Mol Cancer Res 8: 1601-1609.

128. Steinbach G, Lynch PM, Phillips RK, Wallace MH, Hawk E, et al. (2000) The effect of celecoxib, a cyclooxygenase- 2 inhibitor, in familial adenomatous polyposis. N Engl J Med 342: 1946-1952.

129. Brown JR, DuBois RN (2005) COX-2: a molecular target for colorectal cancer prevention. J Clin Oncol 23: 2840-2855.

130. Matsuzawa SI, Reed JC (2001) Siah-1, SIP, and Ebi collaborate in a novel pathway for beta-catenin degradation linked to p53 responses. Mol Cell 7: 915-926.

131. Liu J, Stevens J, Rote CA, Yost HJ, Hu Y, et al. (2001) Siah-1 mediates a novel beta-catenin degradation pathway linking p53 to the adenomatous polyposis coli protein. Mol Cell 7: 927-936.

132. Gonzalez-Moreno S, Gonzalez-Bayon LA, Ortega-Perez G (2010) Hyperthermic intraperitoneal chemotherapy: Rationale and technique. World J Gastrointest Oncol 2: 68-75.

133. Feist M, Huang X, Müller JM, Rau B, Dubiel W (2014) Can hyperthermic intraperitoneal chemotherapy efficiency be improved by blocking the DNA repair factor COP9 signalosome? Int J Colorectal Dis 29: 673-680.

134. Leppert U, Henke W, Huang X, Müller JM, Dubiel W (2011) Posttranscriptional fine-tuning of COP9 signalosome subunit biosynthesis is regulated by the c-Myc/Lin28B/let-7 pathway. J Mol Biol 409: 710-721.

135. Loda M, Cukor B, Tam SW, Lavin P, Fiorentino M, et al. (1997) Increased proteasome-dependent degradation of the cyclin-dependent kinase inhibitor p27 in aggressive colorectal carcinomas. Nat Med 3: 231-234. 